\title{
RIVALIDADE E SOLIDARIEDADE ENTRE IRMÃOS NA CLÍNICA COM FAMÍLIAS
}

\author{
Andrea Seixas Magalhães \\ Pontifícia Universidade Católica do Rio de Janeiro \\ Mayla Cosmo Monteiro \\ Pontifícia Universidade Católica do Rio de Janeiro \\ Cristina Ribeiro Dantas \\ Pontifícia Universidade Católica do Rio de Janeiro
}

\begin{abstract}
Resumo
Este estudo faz parte de uma pesquisa mais ampla sobre fratria e teve como objetivo investigar rivalidade e solidariedade nas relações entre irmãos no contexto da clínica com famílias. Ressalta-se que tanto a rivalidade quanto a solidariedade fraterna são elementos importantes a serem trabalhados no processo psicoterápico da família. Utilizou-se o método clínico-qualitativo de investigação, com base no material clínico coletado durante o período de avaliação familiar em serviço de psicologia aplicada de uma universidade privada. Para fins deste trabalho, ilustramos a discussão com vinhetas clínicas de três famílias, com as seguintes configurações familiares: uma casada, uma monoparental e uma recasada. Concluímos que a presença de rivalidade e solidariedade entre irmãos está relacionada ao manejo parental dos conflitos em diferentes tipos de configurações familiares.
\end{abstract}

Palavras-chave: irmãos; solidariedade; rivalidade; conflitos familiares; psicoterapia familiar.

\section{RIVALRY AND SOLIDARITY BETWEEN SIBLINGS IN THE CLINIC WITH FAMILIES}

\begin{abstract}
This study is part of a wider research on siblings and aimed to investigate rivalry and solidarity in sibling relations in the context of the clinic with families. It is emphasized that both rivalry and fraternal solidarity are important elements to be worked on in the family psychotherapeutic process. The clinical-qualitative method of investigation was used, based on the clinical material collected during the period of family evaluation in the service of internship psychology of a private university. For the purpose of this work, we illustrate the discussion with clinical vignettes of three families, with the following family configurations: one married, one single parent and one remarried. We conclude that the presence of rivalry and solidarity between siblings is related to parental handling of conflicts in different types of family configurations.

Keywords: siblings, solidarity; rivalry; family conflicts; family psychotherapy.
\end{abstract}




\title{
RIVALIDAD Y SOLIDARIDAD ENTRE HERMANOS EN LA CLÍNICA CON FAMÍLIAS
}

\begin{abstract}
Resumen
Este estudio és parte de una investigación más amplia sobre fratería y tuvo como objetivo investigar rivalidad y solidaridad en las relaciones entre hermanos en el contexto de la clínica con familias. Se resalta que tanto la rivalidad como la solidaridad fraterna son elementos importantes a ser trabajados en el proceso psicoterápico de la familia. Se utilizó el método clínico-cualitativo de investigación, con base en el material clínico recogido durante el período de evaluación familiar en servicio de psicología aplicada de una universidad privada. Para fines de este trabajo, ilustramos la discusión con viñetas clínicas de tres familias, con las siguientes configuraciones familiares: una casada, una monoparental y una recasada. Concluimos que la presencia de rivalidad y solidaridad entre hermanos está relacionada al manejo parental de los conflictos en diferentes tipos de configuraciones familiares.

Palabras clave: hermanos; solidaridad; rivalidad; conflictos familiares; psicoterapia familiar.
\end{abstract}

\section{INTRODUÇÃO}

Na família, os irmãos aprendem a negociar, a cooperar e a competir, sendo a relação fraterna permeada constantemente por ambivalência, com a presença simultânea de solidariedade e de rivalidade (Pereira \& Arpini, 2012). A convivência entre irmãos favorece tanto o compartilhamento da vivência de momentos de companheirismo e de apoio emocional (Dunn, 2015) como de conflitos (Howe, Petrakos \& Rinaldi, 1998; Tucker \& Finkelhor, 2017). O manejo adequado de conflitos familiares pode contribuir para a qualidade do relacionamento entre irmãos, influenciando na aquisição de competências sociais importantes. Em certa medida, o envolvimento em situações de conflito pode ser construtivo, contribuindo para que as crianças possam aprender sobre negociação, tomada de iniciativa, compromisso e resolução de problemas (McHale, Kim \& Whitema, 2006). Deskeseredy e Ellis (1997) apontaram que a violência entre irmãos tende a diminuir com a idade e que isto se deve, em parte, ao desenvolvimento de competências de comunicação, resultando na diminuição da violência na resolução de conflitos (Noland, Lilier, McDermott, Coulter \& Seraphine, 2014). Os irmãos constituem um subgrupo primário dentro do grupo familiar e, desta forma, têm a oportunidade de aprender a funcionar como membro de grupos sociais, incluindo o aprendizado do manejo de questões relacionadas à liderança, à igualdade, ao respeito mútuo e às diferenças (Hindle \& Sherwin-White, 2014; Rustin, 2007; White \& Hughes, 2017).

A temática da rivalidade fraterna ocupa um lugar de destaque nas preocupações dos pais e dos profissionais envolvidos com a educação de crianças (Calladine, 1983; Lopes, Fernandes \& Relva, 2017), muito embora a maior parte das interações fraternas envolva cooperação e brincadeira (Abramovitch, Corter, Pepler \& Stanhope, 1986; Dunn, 2015; Howe, Abuhatoum \& Chang-Kredl, 2014). Ressalta-se a importância dos irmãos como fonte de suporte emocional ao longo do ciclo de vida em diferentes contextos de desenvolvimento (Scholte, van 
Lieshout, \& van Aken, 2001; Van der Kaap-Deeder, Vansteenkiste, Soenens \& Mabbe, 2017). Quando as necessidades psicológicas das crianças são satisfeitas, elas são mais propensas a apoiar a autonomia dos irmãos (Van der Kaap-Deeder, Vansteenkiste, Soenens, Loeys, Mabbe \& Gargurevich, 2015). A qualidade dos relacionamentos entre irmãos tanto pode ser promotora (Gass, Jenkins \& Dunn, 2007) quanto dificultadora de saúde emocional (Bowes, Wolke, Joinson, Lereya \& Lewis, 2014), sendo o manejo parental adequado de conflitos familiares fundamental para o estabelecimento de vínculos fraternos solidários, sobretudo quando há traumatismos e/ou crianças com deficiência na família (Scelles, 2003; Sausse \& Scelles, 2017).

A solidariedade pode emergir na fratria, sendo tecida tanto no ato de brincar entre os irmãos quanto em momentos de tensão. De acordo com Kehl (2008) e Birman (2003), na contemporaneidade, novas modalidades de laço fraterno são necessárias nas famílias e na coletividade. A fraternidade, que pode ser desdobrada do relacionamento entre irmãos, é valiosa para lidar com a condição de desamparo humano, tornando-se base para a solidariedade e para a amizade, eixos constituintes dos laços sociais. No passado, também no campo psicanalítico foi dado pouco destaque para o laço fraterno, sobretudo para seus aspectos positivos (Birman, 2003; Hindle \& Sherwin-White, 2014), mas a abordagem psicanalítica da família retoma a discussão sobre a centralidade da fratria na constituição subjetiva mais recentemente (Brusset, 2008; Jaitin, 2006; Kaës, 2008; Kancyper, 2004).

De acordo com a abordagem psicanalítica de grupo familiar, o relacionamento entre irmãos constitui componente central da formação da intersubjetividade. As trocas diárias, os jogos, o compartilhamento de experiências diversas e de conteúdos psíquicos transmitidos no grupo familiar formam a base da fratria. Essa dimensão familiar remonta às origens da instauração da intersubjetividade, narrada por meio do mito da horda primitiva, descrito por S. Freud no texto "Totem e tabu" (1913/1974). De acordo com o referido mito, os filhos, subjugados pelo pai tirânico, que dispunha de todas as mulheres e detinha poder de vida e de morte, eram indivíduos agrupados na medida em que eram igualmente dominados e submetidos à Lei do Pai. A revolta desses filhos leva ao assassinato do pai, à devoração do seu corpo e à incorporação da lei, que a ele estava primariamente vinculada. Assim, emerge a fratria, uma formação intersubjetiva permeada por ambivalência afetiva, e regulada por uma lei compartilhada.

Há, então, uma mudança na forma de agrupamento; os indivíduos que antes eram agregados por submissão, passam a se unir por identificação à figura introjetada do pai. Ocorre uma conversão de agrupamento para grupo, fundado a partir do deslocamento de investimentos grandiosos e das identificações com a figura paterna poderosa para a figura do irmão (Kaës, 2005). A origem do grupo humano, assim como a origem do grupo familiar, está ancorada em processos 
identificatórios primários. Uma vez introjetada a Lei do Pai, os indivíduos se tornam sujeitos identificados entre si, irmãos, na medida em que compartilham a herança paterna. Doravante, o recalcamento dos afetos dirigidos ao pai será também compartilhado entre os irmãos, incluindo hostilidades e idealizações de todas as qualidades que são distribuídas entre eles mesmos. $O$ banquete totêmico (Freud, 1913/1974) dá origem ao banquete de afetos ambivalentes que liga os conteúdos psíquicos transmitidos geracionalmente, e compartilhados entre os irmãos.

A rivalidade pode se apresentar através de implicâncias e de ciúmes, por exemplo, mas sem impedir a formação de alianças entre os irmãos e demonstrações amorosas. Kehl (2000) atribui a rivalidade entre os irmãos, em parte, aos pais que, conscientemente ou não, empregam táticas baseadas na divisão, incentivando entre os filhos a fantasia infantil de que só haveria lugar para o reconhecimento de um no amor parental. Freud (1916-17/1976) ressalta que, quando outras crianças entram em cena, o complexo de Édipo desdobra-se em um complexo de família. A criança se sente prejudicada e, egoisticamente, pode apresentar aversão pelos novos irmãos e irmãs. Emergem, então, as fantasias de eliminar os irmãos. A ênfase dada ao estudo da rivalidade fraterna foi compartilhada por muitos autores psicanalistas (Goldsmid \& Féres-Carneiro, 2011; Hindle \& Sherwin-White, 2014).

A fratria é uma dimensão importante da estrutura familiar que sofre transformações ao longo do ciclo vital da família, sendo o relacionamento entre os irmãos significativamente influenciado pelo relacionamento parental e parento-filial (Minuchin \& Fishman, 1984; Magalhães, Féres-Carneiro, Machado \& Dantas, 2017; Watson \& McGoldrick, 2011; Minuchin, 1982). Salienta-se, contudo, que para além das transformações sofridas pela família, o vínculo entre irmãos é indissolúvel e, na maioria das vezes, o mais duradouro vínculo familiar. As configurações familiares frequentemente são reestruturadas, ocorrendo separações, com ou sem recasamentos subsequentes. Os irmãos apresentam sentimentos e reações diferentes diante das reconfigurações familiares (Neumann \& Zordan, 2013), podendo, ainda assim, desenvolver solidariedade para enfrentar conflitos e rupturas familiares. Além disso, em recasamentos, os meio-irmãos podem favorecer a consolidação dos vínculos familiares com padrastos/madrastas, dependendo do equilíbrio no tratamento e na atenção dada aos filhos por pais biológicos e padrastos/madrastas (Dantas, FéresCarneiro, Machado \& Magalhães, 2019).

$\mathrm{Na}$ clínica com famílias, observa-se que tanto a rivalidade quanto a solidariedade fraterna são elementos importantes a serem trabalhados no processo psicoterápico. Os modos de vinculação fraterna têm sofrido transformações decorrentes das frequentes reconfigurações familiares e da tendência contemporânea à horizontalização das relações familiares, com repercussões na psicodinâmica da família (Magalhães et al., 2017). Portanto, 
ressalta-se a relevância da investigação acerca das relações fraternas e de seus efeitos na intersubjetividade na clínica com famílias. O objetivo do presente estudo foi investigar rivalidade e solidariedade nas relações entre irmãos no contexto da clínica com famílias.

\section{MÉTODO}

Este estudo é parte de uma investigação mais ampla sobre fratria e rede familiar, realizada com onze famílias atendidas pelas equipes de Casal e Família do Serviço de Psicologia Aplicada de uma universidade privada: 4 casadas, 4 recasadas e 3 monoparentais. Utilizou-se metodologia clínico-qualitativa (Turato, 2003), centrada em entrevistas clínicas com famílias e na aplicação da Entrevista Familiar Estruturada - EFE (Féres-Carneiro, 2005), instrumento de avaliação psicológica familiar.

\section{Instrumentos e procedimentos}

Para finalidade de identificação dos diferentes tipos de configuração familiar atendidos na clínica, foi utilizada uma Ficha de Configuração da FamíliaFCF. Nessa ficha, foram registrados dados relativos a idade, sexo, escolaridade, profissão, estado civil, orientação sexual, configuração da família de origem, configuração da família atual, classe social, religião, renda familiar e contribuição individual de cada familiar para a renda total alcançada.

Os dados clínicos foram coletados durante o período da avaliação familiar, que consiste em quatro a seis sessões, aproximadamente. No processo de avaliação familiar, são realizadas entrevistas clínicas preliminares e a Entrevista Familiar Estruturada -EFE (Féres-Carneiro, 2005) sendo parte da rotina da clínica-escola a realização da avaliação familiar antes do início do tratamento psicoterápico propriamente dito.

As entrevistas e a aplicação do instrumento diagnóstico foram realizadas por estagiários, registradas segundo o modelo de relato clínico; a EFE foi gravada e, posteriormente, transcrita. A EFE é um método clínico de avaliação das relações familiares composto de seis tarefas, cinco verbais e uma não verbal, das quais duas tarefas (um e quatro) são propostas à família como grupo e as outras (dois, três, cinco e seis), a cada membro individualmente. Essa técnica permite avaliar as seguintes categorias da interação familiar: comunicação, papéis, liderança, manifestação da agressividade, afeição física, interação conjugal, individualização, integração, autoestima e promoção de saúde emocional.

A partir da $F C F$, foram analisados e identificados os tipos de configuração familiar. Os dados clínicos coletados por meio das entrevistas preliminares e da aplicação da EFE foram analisados no contexto da avaliação psicodiagnóstica familiar, tendo sido focalizada a dimensão da fratria, para atingir os objetivos da pesquisa mais ampla. 


\section{Considerações éticas}

Este projeto foi submetido ao Comitê de Ética em Pesquisa da Universidade e desenvolvido após a sua aprovação. Todos os membros das famílias participantes da pesquisa assinaram o Termo de Consentimento Livre e Esclarecido, concordando com a utilização dos dados clínicos para fins de ensino, pesquisa e publicação científica, com a garantia da preservação das suas identidades.

\section{RESULTADOS E DISCUSSÃO}

Emergiram diversas categorias clínicas de análise. Para fins deste estudo, discutimos a categoria rivalidade/solidariedade entre irmãos a partir de ilustrações clínicas de três famílias, com as seguintes configurações familiares: uma casada (Família Mendonça), uma monoparental (Família Lourenço) e uma recasada (Família Siqueira). Foram observadas repercussões do manejo parental dos conflitos familiares na relação entre os irmãos.

\section{Família Mendonça}

A Família Mendonça, formada pelo casal Anderson (47 anos) e Sheila (44 anos) e suas duas filhas, Sandra (23 anos) e Sofia (10 anos), fora encaminhada para o setor de psicoterapia de família da clínica-escola pela psicoterapeuta de Sofia, que fazia psicoterapia individual na mesma instituição há alguns meses, tendo apresentado sintomas de insegurança e terror noturno. No período de avaliação familiar, constatou-se que os sintomas apresentados por Sofia estavam relacionados a conflitos conjugais dos seus pais, os quais repercutiam nos vínculos parento-filiais e fraternos. Os conflitos conjugais reverberavam no relacionamento das filhas com os pais e no relacionamento das irmãs, gerando conflitos familiares.

Inicialmente, o casal foi escutado sem as filhas. Embora não houvesse uma demanda inicial de psicoterapia para o casal, a esposa trouxe muitas queixas sobre o marido, como: "dificuldades de escutar"; "desatenção"; "não leva nada a sério"; "faz brincadeiras inconvenientes e constrangedoras em público". Sheila também se queixou de sobrecarga nas tarefas de casa e no cuidado com a administração das finanças da família. Ela trabalhava como doméstica diarista e organizava as contas do marido, que era taxista, justificando que ele era muito desorganizado. Anderson concordava com ela, mas parecia se sentir repreendido pela esposa. Nas primeiras entrevistas com o casal, os sintomas de Sofia foram pouco mencionados e os conflitos conjugais emergiram espontaneamente. A vida sexual conjugal estava muito empobrecida e havia pouca privacidade, pois Sofia dormia no quarto dos pais.

Quando questionados sobre o relacionamento com as filhas, relataram diferenças importantes nos modos de se relacionar com cada uma delas. Sandra 
trabalhava e estudava, tinha pouco convívio com os pais e com a irmã, e era distante afetivamente de todos, sobretudo do pai. Já Sofia era extremamente apegada a ele. Sheila ressaltou que Anderson tinha uma relação muito difícil com Sandra e era muito carinhoso com Sofia. Ele se justificou, dizendo que o modo de "se relacionar com uma criança é diferente do modo de se relacionar com uma moça", mas que "cumpre papel de pai com as duas". Sheila também demonstrou que se sentia um pouco mais distante emocionalmente da filha mais velha, que era pouco colaborativa nas tarefas domésticas e ficava muito isolada no seu quarto. Sandra, contudo, recorria à mãe quando precisava de algum apoio emocional. Chamou atenção, ainda, o fato de Sofia dormir no quarto dos pais, alegando sentir-se insegura dormindo no quarto com a irmã. As duas filhas/irmãs pareciam estar muito distanciadas emocionalmente e havia pouca solidariedade entre elas, evidenciando-se uma espécie de cisão na fratria, embora sem conflitos ou rivalidades aparentes.

As diferenças geracionais entre as duas filhas, uma criança e uma jovem adulta, eram evidentes e contribuíam para o afastamento entre elas. Contudo, nas falas dos pais, a excessiva demarcação de diferenças no modo de se relacionar com as duas filhas sinalizava conflitos familiares subjacentes. Na medida em que a investigação acerca dos diferentes modos de vinculação dos pais com cada filha foi aprofundada, o casal trouxe o relato de um evento traumático que se revelou como uma motivação para o distanciamento emocional de Sandra e para o apego excessivo de Sofia.

Ao tentar identificar a origem do distanciamento entre Anderson e a filha mais velha, de quem era bastante próximo quando ela era criança, o casal relatou um episódio de infidelidade conjugal ocorrido quando Sandra tinha dezesseis anos e Sofia tinha três anos. Sheila descobriu que Anderson se envolveu emocionalmente com outra mulher, houve muitas brigas e as filhas presenciaram algumas discussões do casal. Sandra, que era adolescente, apoiou a mãe contra o pai, tendo sido empurrada por ele durante uma das brigas. Anderson contou que "se descontrolou e que ficou muito deprimido" após esse episódio. Relatou que "sentia vergonha dessa época", que "não gosta de falar sobre esse assunto" e que "teve que provar para todos que não era esse tipo de homem". O casal se reconciliou, mas os pais nunca conversaram com a filha mais velha sobre os conflitos familiares relacionados à traição, transformando esse assunto em um tabu familiar. O casal pôde elaborar algumas questões que envolviam a conjugalidade, mas não houve espaço para elaboração daquelas que transbordaram para a parentalidade, atingindo a relação dos pais com as filhas.

Anderson e Sheila consideraram que, após esse episódio, Sandra se afastou do pai. Segundo a mãe, anteriormente, "ela via o pai como homem perfeito". A partir de então, a filha mais velha tornou-se a depositária do conflito conjugal e a mais nova assumiu a função de unir os pais. Desdobraram-se, nessa família, dois tipos de triangulação familiar (Kerr \& Bowen, 1988; Bowen, 1991), 
cada filha fez aliança com um dos pais, representando união e separação no casal conjugal. A triangulação familiar caracteriza-se pelo envolvimento de um membro da família numa relação conflituosa com excessiva carga emocional estabelecida por uma díade. Nos conflitos conjugais, muitas vezes, os filhos ocupam essa posição de terceiro, absorvendo a carga emocional excessiva para reequilibrar o sistema familiar temporariamente. Nesses casos, os filhos sofrem prejuízos no seu processo de diferenciação e na aquisição de autonomia.

A insegurança excessiva de Sofia e o seu apego ao pai simbolizavam o medo da separação do casal, sendo o sintoma de terror noturno uma forma de manter paradoxalmente os pais unidos por meio da sua presença no quarto de casal. O distanciamento afetivo de Sandra do pai e da irmã, por outro lado, simbolizava o afastamento do casal. Consequentemente, houve uma cisão na fratria e o relacionamento das irmãs foi esvaziado de afeto, dificultando a construção de solidariedade entre as irmãs. Os pais passaram a depositar elementos afetuosos no relacionamento com a filha mais nova e elementos hostis no relacionamento com a mais velha. Nessa família, havia um conflito de lealdade (Boszormenyi-Nagy \& Spark, 1973/2012) entre a filha mais velha e os pais, dificultando tanto a relação parento-filial quanto a relação fraterna.

$\mathrm{Na}$ sessão de aplicação da EFE, quando foi abordado o modo como a família usufrui do tempo livre, as filhas uniram-se e tomaram a palavra para descrever a relação do casal, relatando que "eles não tinham momentos juntos", expressando suas percepções acerca do empobrecimento da conjugalidade dos pais. No encaminhamento psicoterápico dado ao final da avaliação familiar apontou-se a importância de abordar e de ressignificar a situação traumática com o objetivo de restituir ao casal conjugal a função de resolução de suas questões íntimas, e de delimitar as fronteiras entre os subsistemas conjugal e parental. Foram propostas sessões intercaladas com o casal e com a família, visando a elaborar os conflitos familiares, com ênfase nos conflitos de lealdade familiar, assim como a restaurar a solidariedade entre as irmãs, liberando-as da triangulação familiar patológica.

\section{Família Lourenço}

A Família Lourenço, de configuração familiar monoparental, era composta pelo pai Roberto (50 anos), e seus dois filhos, Isabela (14 anos) e Igor (12 anos), que moravam com ele há aproximadamente dois anos em uma favela da cidade do Rio de Janeiro. A família monoparental é constituída por um núcleo familiar formado por uma mãe ou um pai que vive com filhos dependentes, sem a presença do outro genitor ou de alguém que o substitua. A origem desta configuração familiar pode ser a separação, o divórcio, a adoção ou ausência de um dos genitores por abandono (Melo \& Marin, 2016). Na Família Lourenço, embora os filhos visitassem a casa da mãe com alguma frequência, as trocas afetivas entre eles eram muito incipientes, gerando sentimentos de desamparo 
afetivo nos filhos. A mãe fora convocada para entrevistas no período de avaliação familiar, mas nunca respondeu aos chamados. A responsabilidade pela educação e cuidado dos filhos era assumida exclusivamente pelo pai.

Roberto buscou a clínica-escola devido à "falta de interesse dos filhos em tudo" - nos estudos, em atividades extras (esportes, por exemplo) e na colaboração nas tarefas domésticas. Ele sentia-se impotente e preocupado em relação ao futuro dos filhos, e não sabia como lidar com a educação destes. O pai era separado da mãe das crianças há oito anos e não se recasara; a mãe, no entanto, já havia constituído uma nova família, e possuía uma filha (9 meses) da relação atual e outra (18 anos) de uma relação anterior. Ela morava distante dos filhos, em outra favela conhecida por ser uma comunidade bastante violenta. A família Lourenço morava na casa da mãe de Roberto, uma residência de três andares com entradas independentes. No primeiro andar, composto por um cômodo, ficavam as mulheres da família (avó, tia e Isabela); no segundo andar morava um parente sozinho e, no último andar, Roberto e Igor dividiam o mesmo quarto. A mudança dos filhos para a casa do pai foi justificada, principalmente, porque Isabela apresentava dificuldades respiratórias provocadas pelas precárias condições de moradia da mãe.

Isabela mantinha um forte vínculo com sua irmã mais nova, por quem nutria um carinho "maternal". Gostava de cuidar dela e de protegê-la, não só quando passava os finais de semana na casa da mãe - eventualmente, a levava para a casa do pai. A forma com a qual cuidava de sua irmã mais nova sinalizava uma compensação ao seu próprio desamparo advindo da escassa presença materna. Isabela cuidava de sua irmã tal como gostaria de ter sido cuidada por sua mãe.

Na avaliação psicodiagnóstica, observaram-se dificuldades no exercício da parentalidade e na expressão afetiva familiar. Essas dificuldades emergiam no contexto de mudanças no ciclo familiar, como a adolescência dos filhos, e dos lutos pela saída da casa da mãe. Os papéis familiares eram pouco delimitados e Roberto, por vezes, não conseguia exercer sua autoridade parental, comportando-se como uma espécie de irmão mais velho em muitos momentos. Ademais, sua atenção e preocupação voltavam-se mais para Igor do que para Isabela, que ficava mais isolada na dinâmica familiar. Em famílias monoparentais, as relações pais-filhos tendem a ser mais horizontalizadas (Ried \& Pereira, 2012), sobretudo quando há pouco apoio da rede familiar, o que era observado nessa família.

O fato de o pai não assumir o papel parental dificultava a vinculação entre os irmãos. Minuchin e Fishman (1984), ao descreverem o holon dos irmãos, o primeiro grupo de iguais do qual a criança participa, ressaltam que, no processo de interação entre eles - nas trocas afetivas, nas brigas, nos momentos de diversão - vão aprendendo a negociar, a cooperar, a competir e a se posicionar. Este processo promove tanto seu sentimento de pertencimento a um grupo como 
a sua individualidade. Desta convivência, derivam os laços de afeto e de solidariedade. Na fratria em questão não existiam conflitos aparentes, tampouco uma formação solidária; componentes como intimidade e cumplicidade estavam ausentes na relação fraterna entre Isabela e Igor. Havia também a dificuldade na expressão afetivo-emocional na família, não havendo espaço para o compartilhamento de medos e sofrimentos. Era preciso compreender as vivências internas uns dos outros para favorecer a intimidade familiar.

Observou-se que o isolamento de Roberto (social e familiar) e a falta de apoio da rede familiar no exercício da parentalidade intensificavam suas inseguranças relacionadas ao manejo com os filhos. Embora a avó paterna e a tia fornecessem apoio instrumental, cuidando da alimentação e da casa, havia pouco apoio emocional no cuidado com os filhos. A avó tinha relação conflituosa com os netos, com brigas e reclamações constantes. A mãe deles, segundo o pai, tinha temperamento difícil e era instável emocionalmente. Ao mesmo tempo em que exigia dos filhos manifestações afetivas amorosas, reagia agressiva e descontroladamente quando estes a desobedeciam, sobretudo Igor. Berenstein (2001) define a família como um conjunto vincular formado por pactos e acordos inconscientes, os quais a estruturam e designam um modo de processar o prescrito e o proibido. Os pactos e acordos, por serem inconscientes, não são enunciados nem formulados, mas aparecem nas produções familiares e em suas maneiras de se vincular e construir vínculo familiar. Weissman (2017) destaca que cada família, ao longo do tempo, tem o dever de se reestruturar e de se reescrever. Os pactos e acordos inconscientes que configuraram a família com filhos crianças devem ser reescritos quando da entrada dos filhos na adolescência, e assim por diante. A busca da família Lourenço pela psicoterapia evidenciou a necessidade de os membros se reestruturarem diante desta nova configuração familiar.

A questão do desamparo era um dos aspectos centrais do funcionamento psíquico dessa família. Roberto sentia-se muito desvalorizado e deslegitimado por sua mãe, que também não conseguiu fomentar a solidariedade afetiva entre seus filhos. Isabela e Igor sentiam-se abandonados pela mãe e não encontravam suporte parental suficiente. Havia, portanto, um sentimento de nãopertencimento que fazia parte da atmosfera familiar. Isso se refletia na psicodinâmica familiar pai-filhos; Roberto protegia os filhos, mas não era capaz de acolhê-los emocionalmente. Weissmann (2017) aponta que o grande desafio do século XXI é a mobilidade, a complexidade e a labilidade nos vínculos e em suas formas sociais. Ao mesmo tempo em que a maior abertura e a maior liberdade possibilitam e oportunizam ao sujeito contemporâneo uma diversa criação de vínculos, este se sente desamparado, indagando-se acerca de como ocupar os lugares que fazem parte da estrutura social e familiar.

$\mathrm{Na}$ avaliação familiar, a análise da EFE, sobretudo das categorias autoestima, papéis familiares e afeição física, evidenciou o funcionamento 
horizontalizado da família, que se apresentava como uma família de "irmãos". A autoestima dos membros da família estava diminuída, apesar de a capacidade de buscar ajuda estar preservada em todos eles. Porém, apresentavam pouca confiança no recebimento de apoio, sobretudo das figuras parentais. A busca de apoio foi deslocada para os pares (relações horizontais) e o pai se colocou em posição infantilizada no grupo familiar. A delimitação de papéis familiares revelou-se pouco clara e a individualização dos membros se mostrou precária. Em quase todas as tarefas, o pai comportava-se de modo semelhante aos filhos, mostrando dificuldades em assumir o papel parental e de se diferenciar deles. Observou-se constrangimento quanto à manifestação de afeição física, um indicador de que havia bloqueios na intimidade familiar. Conclui-se que a dificuldade de Roberto em assumir o lugar parental, a baixa autoestima dos membros da família e a falta de intimidade familiar dificultaram a consolidação dos vínculos fraternos, mantendo a família apartada emocionalmente.

\section{Família Siqueira}

A família Siqueira, composta pelo casal Paulo (41 anos) e Marta (38 anos), e pelos filhos, Thiago ( 8 anos), filho do primeiro casamento de Marta, e Pedro (6 anos), filho do casal, buscou atendimento devido às constantes brigas familiares. Ao relatarem os motivos dos conflitos, os relacionaram, Paulo de maneira mais enfática, às interferências dos pais de Marta, na criação de Thiago e Pedro. A família Siqueira residia com D. Elza, mãe de Marta, que estava separada há alguns anos. Paulo acreditava que, tanto a sogra quanto o sogro, preferiam Thiago a Pedro e, para compensar esta suposta predileção, Paulo superprotegia Pedro, provocando conflitos conjugais e com a família de Marta. Importante sublinhar que Paulo e Marta estavam desempregados e dependiam financeiramente de suas famílias de origem. Marta trabalhava esporadicamente, realizando eventos, o que causava muitos ciúmes em Paulo. Com relação à sua situação financeira, Paulo se sentia inferiorizado, com a autoestima bastante comprometida.

Ao longo do período de avaliação familiar, verificou-se que os conflitos conjugais estavam relacionados às discordâncias entre Paulo e Marta acerca dos cuidados destinados aos filhos, além da dificuldade de ambos em estabelecerem fronteiras nítidas com os pais de Marta, que, segundo Paulo, "se metem" na maneira como eles cuidam dos filhos. Foi possível observar a dificuldade dos membros do casal em separarem os aspectos pertinentes à conjugalidade daqueles relativos à parentalidade. Havia dificuldade em legitimar a autoridade parental, uma vez que se encontravam enredados emocionalmente às suas famílias de origem, sobretudo aos pais de Marta. A este respeito, mencionaram que quando estão somente os dois "é pleno", quando estão com os filhos "é mais ou menos" e quando estão com a família de Marta "é só briga". 
As fronteiras difusas entre os subsistemas conjugal e parental, constituídos pela díade Paulo e Marta, eram constantemente atravessadas pelos sogros, dificultando a diferenciação e proteção aos membros da família, além de favorecer o emaranhamento com as famílias de origem e exacerbar os conflitos conjugais. Ademais, também foi possível notar que Paulo e Marta encontravamse bastante regredidos e incapacitados para exercerem suas funções familiares de maneira eficaz. A este tipo de organização familiar subjaz o medo da separação que favorece a aglutinação familiar, criando obstáculos para o reconhecimento da alteridade de seus membros.

Paulo parecia se sentir inferior em relação à família de Marta, conforme observado nas entrevistas com o casal. Ele projetava elementos relacionados à sua baixa autoestima em Pedro, repetindo incessantemente que os sogros preferiam o filho do primeiro casamento de Marta. Esta contou que morou no exterior com o primeiro marido, do qual se separou quando estava grávida de Thiago. Seu ex-marido continuava morando distante; pai e filho se encontravam esporadicamente. Convém ressaltar que Paulo e Marta constituíam uma família recasada, na qual um ou ambos os cônjuges possuem filhos de relacionamentos anteriores. A configuração da família Siqueira segue o modelo substitutivo (Lobo, 2009), uma vez que o pai de Thiago, devido à sua ausência, foi substituído, em suas funções parentais, por Paulo. Enquanto no modelo cumulativo o padrasto e/ou a madrasta ingressam na família recasada, compartilhando as funções parentais com o pai e a mãe, no modelo substitutivo a entrada da madrasta e do padrasto no cenário familiar ocorre concomitante à saída do pai e/ou da mãe (Pryor, 2014). Assim sendo, o modo como Thiago e Paulo se conheceram e constituíram um relacionamento, a história de vida de Thiago antes da chegada de Paulo, a relação entre os irmãos, entre outras especificidades dessa família envolvem complexidades que precisam ser consideradas. O recasamento suscita reorganizações dos vínculos familiares, tornando o sistema de parentesco mais flexível ao mesmo tempo em que possibilita novas construções e ressignificações das regras, dos papéis e da delimitação de fronteiras nítidas entre os subsistemas parental, conjugal e fraterno (Dantas et al., 2019).

Marta relatou que Thiago estava agressivo na escola, falando palavrões, atribuindo este comportamento às brigas entre Paulo e ela. Ao serem indagados se as crianças presenciavam as brigas entre os membros do casal, eles responderam que "sim". Marta contou que os filhos não aguentavam mais presenciar as brigas dos pais. Entretanto, Paulo achava que os filhos precisavam saber o que se passava com o casal.

O transbordamento dos conflitos no âmbito da conjugalidade tende a afetar negativamente todos os subsistemas familiares. Pode-se pensar no conceito de spillover (Hameister, Barbosa \& Wagner, 2015) como um transbordamento dos afetos nas interações conjugais para as parentais, podendo ter um impacto negativo nas relações pais-filhos, assim como na aquisição de 
autonomia dos filhos. Tal conceito sustenta que os sentimentos expressos em um subsistema influenciam e recebem influências dos estados emocionais vivenciados nos demais subsistemas familiares (Erel \& Burman, 1995). No que tange à expressão de agressividade de Thiago na aplicação da EFE, evidenciouse certa inibição a partir da dificuldade apresentada por ele em responder de maneira espontânea quando indagado pelas psicoterapeutas sobre a tarefa que avalia a manifestação da agressividade. Relacionamos tal inibição às tensões emocionais advindas da díade parental, ao efeito spillover, e também ao fato de Thiago não poder expressar sua agressividade para o padrasto, temendo perder seu amor.

Quando questionados sobre os filhos, Paulo disse que Thiago machucava Pedro quando eles eram menores e por isso o chamava de "Diabo". Os psicoterapeutas sinalizaram que o irmão mais velho estava provavelmente com ciúmes do mais novo e que, como Pedro era filho biológico de Paulo, talvez Thiago sentisse que Paulo dava mais carinho e atenção a ele. Paulo demonstrava maior intimidade e cumplicidade com Pedro, e Thiago parecia se sentir excluído da relação pai-filhos. No caso de haver distinção, por parte dos genitores e/ou padrastos e madrastas, no tratamento entre os irmãos, o estabelecimento da relação fraterna pode ser dificultado, exacerbando a rivalidade e a competição entre eles (Oliveira, 2006).

Observou-se que o grande desequilíbrio no tratamento de Paulo com os filhos pode favorecer o surgimento de conflitos fraternos futuros, contribuindo para o surgimento da rivalidade fraterna. A rivalidade no contexto da fratria é considerada um sentimento legítimo desenvolvido pela criança ao se deparar com alguém com quem precisará dividir o amor dos pais. Caracterizadas pela ambivalência de sentimentos, as relações entre os irmãos servem como experimento para as relações sociais posteriores (Pereira \& Lopes, 2013). Destaca-se, neste contexto, a importância do desenvolvimento do sentimento de solidariedade entre os irmãos, uma vez que, por pertencerem à mesma geração e estarem na mesma posição na hierarquia familiar, vivenciam situações que só podem ser compartilhadas entre ambos.

Marta discorda em relação aos cuidados excessivos que Paulo tinha com Pedro em relação à higiene pessoal do menino, dizendo achar que o marido tinha transtorno obsessivo compulsivo. Paulo tratava Pedro como se o menino fosse uma extensão de si mesmo, forçando-o a estudar e proibindo-o de fazer atividades esportivas, ou de visitar o avô materno, argumentando que seu filho não seria igual a ele próprio, que se considerava um advogado frustrado. Para Paulo, Pedro precisa se dedicar aos estudos, pois será um "gênio" no futuro. Na aplicação da EFE, ao serem indagados sobre o que cada um gosta em si, Paulo respondeu por Pedro, relatando que o filho possui uma "mente pensante que podia pensar em menos besteira", e em seguida completou, "você é um bom lutador, por exemplo". Na análise da EFE foi possível perceber que Paulo não 
permitia que Pedro emitisse suas opiniões, como se ele e o filho fossem um único sujeito. O vínculo adesivo ou narcisista dual (Puget \& Berenstein, 1993) não permitia que Pedro se descolasse de seu pai, pois ele depositava no menino seus aspectos narcísicos fragilizados. Curioso notar que, enquanto Pedro era considerado pelas professoras um menino independente, Paulo prosseguia seus rituais excessivos de limpeza, infantilizando o filho.

O casal relatou que Paulo dormia em um colchão no chão com o filho mais novo e que Marta dormia com Pedro, na cama do casal. Pode-se pensar que o empobrecimento do casal conjugal aparece na maneira como Paulo e Marta dormiam, sugerindo que os lugares nesta família pareciam estar equivocados. Ao não ocuparem seus lugares, os membros do casal subvertiam a ordem familiar, formando dois subsistemas - um contendo pai e Pedro e o outro, mãe e Thiago. Assim, o funcionamento precário e infantilizado do subsistema conjugal, emaranhado com a família de Marta, dificultava o exercício satisfatório das funções parentais, trazendo repercussões significativas para o relacionamento fraterno.

O encaminhamento psicoterapêutico, a partir da análise da EFE e das entrevistas preliminares, buscou promover a reflexão acerca do desempenho dos papéis familiares, sobretudo os assumidos de maneira ineficiente por Marta e Paulo. Neste panorama, o fortalecimento do subsistema conjugal, composto por Marta e Paulo, poderia mitigar as interferências das famílias de origem de ambos, além de preservar os filhos das questões que não lhes pertencem, protegendo, por conseguinte, o subsistema fraterno.

\section{CONSIDERAÇÕES FINAIS}

Na clínica com famílias, a fratria se apresenta como uma dimensão intersubjetiva importante, sendo o conhecimento sobre os modos de vinculação dos irmãos nas diferentes configurações familiares fundamental para a avaliação psicodiagnóstica familiar e para o manejo dos conflitos familiares em psicoterapia. A família é uma formação grupal extremamente dinâmica e complexa, atravessada por influências geracionais e socioculturais, que se estrutura por meio da formação de subsistemas que interagem entre si. Os subsistemas familiares - conjugal, parental, parento-filial e fraterno, dentre outros tantos possíveis - possuem regras e funções específicas delineadas em cada família de acordo com suas necessidades instrumentais e emocionais. Eles são organizados com a finalidade de enfrentar os desafios do ciclo vital familiar e os acontecimentos que permeiam a vida de modo mais amplo, incluindo eventos traumáticos.

Na sociedade moderna, regida por uma lógica tradicional e hierárquica, os modos de vinculação familiar eram pré-determinados a partir de demandas voltadas, sobretudo, para a sobrevivência do grupo, e havia mais estabilidade no 
desenvolvimento do ciclo vital. Na contemporaneidade, deparamo-nos com configurações familiares mais complexas, regidas pela lógica igualitária, num mundo com parâmetros pouco estáveis. Esse panorama sociocultural impõe novos desafios à família, como a necessidade de responder às mudanças com mais agilidade e plasticidade, considerando as constantes reconfigurações de papéis socioculturais que interagem e moldam os papéis familiares. Ser pai, ser mãe, ser casal, ser irmão, ser avós, resulta de constantes construções e reconstruções identitárias. Os modos de vinculação familiar estão na base do desempenho dos papéis familiares. Os irmãos formam a fratria a partir dos diversos modos de vinculação familiar, modos que são transmitidos entre as gerações, mas que se transformam na medida em que também ocorrem reconfigurações familiares, deflagradas por casamentos, recasamentos, separações, nascimentos, afastamentos, perdas e outros eventos significativos.

Mesmo quando o arranjo familiar permanece o mesmo e a família permanece casada, como na ilustração clínica da família Mendonça, o exercício dos papéis parentais pode ser abalado por eventos traumáticos com desdobramentos na fratria. Independentemente do arranjo familiar (casado, recasado, monoparental), identificamos que o que afeta o desenvolvimento da solidariedade e da rivalidade na fratria é o manejo dos conflitos familiares pelos pais. A reconfiguração familiar depende dos arranjos conjugais, mas depende, sobretudo, do modo de estabelecer os vínculos familiares e da consistência no exercício dos papéis familiares, que são sempre interdependentes entre si. Diante de conflitos conjugais e/ou familiares, as triangulações, por vezes prevalecem, dificultando a circulação dos afetos e a elaboração de questões intersubjetivas necessária para a consolidação dos vínculos.

Destacamos também que, na clínica com famílias recasadas, conforme ilustrado por meio da Família Siqueira, deve-se ter atenção especial ao tratamento dado aos meio-irmãos, que podem ser mais suscetíveis às triangulações com os pais biológicos, em detrimento da solidariedade na fratria. Já na clínica com famílias monoparentais, quando a rede familiar é precária, como na Família Lourenço, pode ocorrer uma fragilização do exercício da parentalidade, considerando que somente um dos pais concentra as funções de cuidado parental, bem como maior horizontalização das relações familiares. Nesses casos, o pai/mãe tende a se colocar no lugar de irmão/irmã, esvaziando a função parental e desconfigurando a fratria. Na psicoterapia familiar, é necessário fornecer suporte para o exercício consistente dos papéis parentais para que os irmãos se vinculem de modo saudável. Sendo assim, esse estudo buscou contribuir com subsídios teórico-clínicos para que os psicoterapeutas de família possam intervir no sentido da discriminação dos afetos no relacionamento entre irmãos, elaborando questões relativas à rivalidade e à solidariedade na fratria, e promovendo a saúde emocional familiar. 


\section{DECLARAÇÃO DE CONFLITOS DE INTERESSE}

Não há conflitos de interesse.

\section{REFERÊNCIAS}

Abramovitch, R., Corter, C., Pepler, D., \& Stanhope, L. (1986). Sibling and peer interactions: A final follow-up and a comparison. Child Development, 57, 217-229. http://dx.doi.org/10.2307/1130653

Berenstein, I. (2001). El sujeto y el otro: De la ausencia a la presencia. Buenos Aires: Paidós.

Birman, J. (2003). Fraternidades: destinos e impasses da figura do pai na atualidade. Physis: Revista de Saúde Coletiva, 13(1), 93-114. https://dx.doi.org/10.1590/S0103-73312003000100005

Boszormenyi-Nagy, I., \& Spark G. (2012). Lealtades invisibles. Buenos Aires: Amorrortu. (Trabalho original publicado em 1973)

Bowen, M. (1991). De la familia al individuo: La diferenciación del sí mismo en el sistema familiar. Barcelona: Paidós.

Bowes, L., Wolke, D., Joinson, C., Lereya, S. T., \& Lewis, G. (2014). Sibling bullying and risk of depression, anxiety, and self-harm: a prospective cohort study. Pediatrics, 134, 1032- 1039. http://dx.doi .org/10.1542/peds.20140832

Brusset, B. (2008). Le lien fraternel et la psychanalyse. Revue française de psychanalyse, 72, 347-382. http://dx.doi.org/10.3917/rfp.722.0347

Calladine, C. (1983). Sibling rivalry: a parent education perspective. Child Welfare Journal, 62(5), 421-427.

Dantas, C.R., Féres-Carneiro, T. Machado, R.N., \& Magalhães, A.S. (2019). Repercussões da parentalidade na conjugalidade do casal recasado: revelações das madrastas. Revista Psicologia Teoria e Pesquisa, 35, 1-16. https://dx.doi.org/10.1590/0102.3772e3545

Deskeseredy, W., \& Ellis, D. (1997). Sibling violence: a review of canadian social research and suggestions for further empirical work. Humanity and Society, 21, 397- 411. https://doi.org/10.1177/016059769702100405

Dunn, J. (2015). Siblings. In J. E. Grusec, \& P. D. Hastings (Eds.), Handbook of socialization: Theory and research (pp. 182-201). New York, NY: Guilford Press.

Erel, O., Burman, B. (1995). Interrelatedness of marital relations and parentchild relations: a meta-analytic review. Pshychological Bulletin, 118(1), 108-132.

Féres-Carneiro, T. (2005) Entrevista familiar estruturada: Um método clínico para avaliação das relações familiares. São Paulo: Casa do Psicólogo. 
Freud, S. (1976). Conferências introdutórias sobre psicanálise. In Edição Standard Brasileira das Obras Psicológicas Completas de Sigmund Freud (Vol. XVI, pp.289-539). Rio de Janeiro: Imago. (Trabalho original publicado em 1916-1917).

Freud, S. (1974). Totem e tabu. (J. Salomão, Trad.). In Edição Standard Brasileira das Obras Psicológicas Completas (Vol. XIII, pp. 13-168). Rio de Janeiro: Imago. (Trabalho original publicado em 1913)

Gass, K., Jenkins, J., \& Dunn, J. (2007). Are sibling relationships protective? A longitudinal study. Journal of Child Psychology and Psychiatry and Allied Disciplines, 48, 167-175. http://dx.doi.org/10.1111/j.14697610.2006.01699.x

Goldsmid, R., \& Féres-Carneiro, T. (2011). Relação fraterna: constituição do sujeito e formação do laço social. Psicologia USP, 22(4), 771-788. http://dx.doi.org/10.1590/S0103-65642011005000031.

Hameister, B.R., Barbosa, V.P. \& Wagner, A. (2015). Conjugalidade e parentalidade: uma revisão sistemática do efeito spillover. Arquivos Brasileiros de Psicologia, 67(2), 140-155.

Hindle, D., \& Sherwin-White, S. (Eds.). (2014). Sibling matters: A psychoanalytic, developmental, and systemic approach. London, England: Karnac Books.

Howe, N., Petrakos, H., \& Rinaldi, C. (1998). All the sheeps are dead. He murdered them: Sibling pretense, negotiation, internal state language, and relationship quality. Child Development, 69(1), 182-191. http://dx.doi.org/10.2307/1132079

Howe, N.; Abuhatoum, S., \& Chang-Kredl, S. (2014). Everything's upside down. We'll call it upside down valley!: siblings' creative play themes, object use, and language during pretend play. Early Education and Development, 25(3), 381-398. http://dx.doi.org/10.1080/10409289.2013.773254

Jaitin R. (2006). Cliniques de l'inceste fraternel. Paris, France: Dunod.

Kaës, R. (2005). Os espaços psíquicos comuns e partilhados: Transmissão da negatividade. São Paulo: Casa do Psicólogo.

Kaës, R. (2008). Le complexe fraternel. Paris, France: Dunod.

Kancyper, L. (1999). Confrontação de gerações. São Paulo: Casa do Psicólogo.

Kancyper, L. (2004). El complejo fraterno: Estúdio psicanalítico. Buenos Aires: Lúmen.

Kehl, M.R. (2000). Função fraterna. Rio de Janeiro: Relume Dumará.

Kehl, M.R. (2008). A fratria orfã: Conversas sobre a juventude. 1 ed. São Paulo: Olho d'água.

Kerr, M.E., \& Bowen, M. (1988). Family evaluation: An approach based on Bowen theory. New York, NY: Norton.

Lobo, C. (2009). Recomposições familiares: Dinâmicas de um processo de transição. Lisboa, Portugal: Fundação Calouste Gulbenkian. 
Lopes, P.P., Fernandes, O M., \& Relva, I. C. (2017). A violência como tática de resolução de conflitos entre irmãos. Revista Crítica de Ciências Sociais, 113 http://dx.doi.org/10.4000/rccs.6696

Magalhães, A.S.; Féres-Carneiro, T.; Machado, R.N. \& Dantas, C.R. (2017). Modos de vinculação na família: a fratria em questão. In T. Féres-Carneiro (Org.), Casal e família: Teoria, pesquisa e clínica (pp. 97-114). Rio de Janeiro: PUC-Rio/Prospectiva.

McHale, S., Kim, J., \& Whitema, S. (2006). Sibling relationships in childhood and adolescence. In: P. Noller \& J. Feeney (Orgs.) Close relationships: functions, forms and processes (pp.127-149). Hove England: Psychology Press.

Melo, S.C.H., \& Marin, A.H. (2016). Influência das composições familiares monoparentais no desenvolvimento da criança: revisão de literatura. Revista da SPAGESP, 17(1), 04-13. Recuperado em 30 de maio de 2019, de http://pepsic.bvsalud.org/scielo.php?script=sci_arttext\&pid=S167729702016000100002\&lng=pt\&tlng=pt.

Minuchin, S. (1982). Famílias: Funcionamento e tratamento. Porto Alegre: Artes Médicas.

Minuchin, S., \& Fishman, H.C. (1983). Técnicas de terapia familiar. Paidós: Barcelona.

Neumann, A., \& Zordan, E. (2013). As reverberações da separação conjugal dos pais no relacionamento entre irmãos. Pensando familias, 17(2), 3547. Recuperado em 30 de maio de 2019, de http://pepsic.bvsalud.org/scielo.php?script=sci_arttext\&pid=S1679494X2013000200003\&lng=pt\&tIng=pt.

Noland, V., Lilier, K., McDermott, R., Coulter, M., \& Seraphine, A. (2014). Is Adolescent Sibling Violence a Precursor to College Dating Violence? American Journal of Health Behavior, 28(1), 13-23.

Oliveira, A.L. (2006). Família e irmãos. In C. M. de Cerveny (Org.), Famílias e narrativas, gênero, parentalidade, irmãos, filhos nos divórcios, genealogia, história, violência, intervenção sistêmica, rede social (pp.63-81). São Paulo: Casa do Psicólogo.

Pereira, C.R.R., \& Arpini, D.M. (2012). Os irmãos nas novas configurações familiares. Psicologia Argumento, 30(69), 275-285.

Pereira, C.R.R., \& Lopes, R.C.S. (2013). Rivalidade fraterna: uma proposta de definição conceitual. Estudos de Psicologia, 18(2), 277-283.

Pryor, J. (2014). Stepfamilies: A global perspective on research, policy and practice. New York: Rutledge.

Puget, J., \& Berenstein, I. (1993). Psicanálise do casal. Porto Alegre: Artes Médicas.

Ried, J., \& Pereira, A.C. (2012). Família monoparental masculina: o cotidiano e suas vicissitudes. Nova Perspectiva Sistêmica, 21(44). 
Rustin, M. (2007). Taking account of siblings: a view from child psychotherapy. Journal of Child Psychotherapy, 33(1), 21-35. https://doi.org/10.1080/00754170701195637

Sausse, S.K., \& Scelles, R. (Eds.). (2017). The clinic of disability: psychoanalytical approaches. London, England: Karnac Books.

Scelles, R. (2003). Frères et sœurs, complices et rivaux. Paris, France: Fleurus.

Scholte, R.H.J., Van Lieshout, C.F.M., \& Van Aken, M.A.G. (2001). Perceived relational support in adolescence: Dimensions, configurations, and adolescent adjustment. Journal of Research on Adolescence, 11, 71-94. http://dx.doi.org/10.1111/1532-7795.00004

Tucker, C.J., \& Finkelhor, D. (2017). The state of interventions for sibling conflict and aggression: a systematic review. Trauma, Violence \& Abuse, 18(4), 396-406. https://doi.org/10.1177/1524838015622438

Turato, E.R. (2003). Tratado da metodologia da pesquisa clínico-qualitativa. Petrópolis, RJ: Vozes.

Van der Kaap-Deeder, J., Vansteenkiste, M., Soenens, B., \& Mabbe, E. (2017). Children's daily well-being: the role of mothers', teachers', and siblings' autonomy support and psychological control. Developmental psychology, 53(2), 237-251. http://dx.doi.org/10.1037/dev0000218

Van der Kaap-Deeder, J., Vansteenkiste, M., Soenens, B., Loeys, T., Mabbe, E., \& Gargurevich, R. (2015). From autonomy-supportive parenting to autonomy-supportive sibling interactions: the role of psychological need satisfaction. Personality and Social Psychology Bulletin, 41, 1590 -1604. http://dx.doi.org/10.1177/0146167215602225

Watson, M.F., \& McGoldrick, M. (2011). Practice with siblings in a cultural context. In Jonathan Caspi (Ed.), Sibling development: Implications for mental health practitioners (pp. 59-81). New York: Springer.

Weissmann, L. (2017). Composições familiares e filiação na contemporaneidade. Revista Brasileira de Psicanálise, 51(4), 159-172.

White, N., \& Hughes, C. (2017). Why siblings matter: the role of brother and sister relationships in development and well-being. London, England: Routledge. 


\section{Sobre as autoras}

Andrea Seixas Magalhães é professora associada do Departamento de Psicologia da PUC-Rio. Doutora em Psicologia Clínica pela PUC-Rio. Coordenadora do Laboratório de Estudos em Família e Casal da PUC-Rio. Recebe financiamento de pesquisa do CNPq e FAPERJ.

andreasm@puc-rio.br

Mayla Cosmo Monteiro é pós-doutoranda em Psicologia Clínica (PUC-Rio / FAPERJ). Doutora em Psicologia Clínica pela PUC-Rio. Membro do Laboratório de Estudos em Família e Casal da PUC-Rio.

mayla.cosmo@uol.com.br

Cristina Ribeiro Dantas é pós-doutoranda em Psicologia Clínica (PUC-Rio / FAPERJ). Doutora em Psicologia Clínica pela PUC-Rio. Membro do Laboratório de Estudos em Família e Casal da PUC-Rio.

c.r.dantas@hotmail.com

A contribuição de cada autor pode ser atribuída como se segue: Andrea Seixas Magalhães, Mayla Cosmo Monteiro e Cristina Ribeiro Dantas contribuíram para a conceitualização, investigação e visualização do artigo; Andrea Seixas Magalhães foi responsável pela obtenção de financiamento; Andrea Seixas Magalhães, Mayla Cosmo Monteiro e Cristina Ribeiro Dantas são as responsáveis pela redação do artigo.

As autoras agradecem ao CNPq e à FAPERJ pelo financiamento da pesquisa. Agradecem, também, ao grupo de pesquisa do LEFaC (Laboratório de Estudos em Família e Casal) composto pelas bolsistas Alessandra Halkjaer-Lassen (IC/CNPq - PIBIC), Bruna Meira (IC/FAPERJ), Ellen Tereza da Silva Faria (IC/PUC-Rio); Flávia Parente (IC/CNPq), Isabella Sucrmont (IC/CNPq), Júlia Meirelles Saraiva (IC/FAPERJ), Maria Eduarda Carneiro Marques (AT / FAPERJ); Patricia Costa (IC/ CNPq - PIBIC) e Valentina da Silveira (IC/ CNPq - PIBIC). 